\section{DEMOGRAPHY AND CLINICAL ACTIVITY OF BELGIAN PAEDIATRICIANS AS ASSESSED BY THE HEAD OF THE DEPARTMENT OF PAEDIATRICS}

P.L. Alliet ${ }^{1,2}$, G. Verellen ${ }^{2}$, M. Alexander ${ }^{2}$, D. Deliège ${ }^{3}$, C. Artoisenet ${ }^{3}$

${ }^{1}$ Paediatrics, Jessa Hospital, Hasselt, ${ }^{2}$ Belgian Academy of Paediatrics, ${ }^{3}$ School of Public Health, University of Louvain, Brussels, Belgium

Introduction: As in other European countries, Belgian hospitals encounter difficulties in recruiting paediatricians. In order to better understand the underlying problem and the needs, it is mandatory to have an insight in the current demography and clinical activity.

Methods: In 2007, a questionnaire was sent to the head of the department of paediatrics in all Belgian hospitals. Demographic characteristics and hospital activities were collected. Data were encoded by two separate persons and compared through a software program.

Results: $55 \%$ of the hospital paediatricians are female $(70-85 \%$ in the cohort $<45$ year of age). The mean number of paediatricians working in a regional department was 6 (29 in university department). $39 / 87$ departments had at least one paediatric resident. In total, 277 residents were recorded, 76 of them working in a regional centre. The mean total clinical hospital workload per hospital, as assessed by a time weight indicator (based on the number of admissions in night and day hospitalizations, outpatient clinic, paediatric emergency and number of births), was significantly higher in an university vs a regional department (5.9 vs 2.1 ). If adapted according to the team size (in FTE, incl. residents), an inverse relationship was seen (1.2 vs. 3.8 ).

Conclusion: There is an ongoing feminization among hospital paediatricians. The mean clinical workload per hospital is higher in an university hospital compared to a regional one. If corrected however for the team size, an inverse relationship is seen. This index is not taking into account the impact of non-clinical activities.

\section{THE COST OF CLOTTING}

\author{
P. Holt, P.B. Baines, S. Jakka \\ Paediatric Intensive Care, Alder Hey Children's \\ NHS, Liverpool, UK
}

Introduction: Blood sampling is important in informing the management of critically ill children, but over sampling may cause anaemia, and is an unnecessary expense. We sought to examine the practice of routine coagulation tests (amongst others) in critically ill children.

Methods: A prospective audit of all critically ill children admitted to a multidisciplinary regional Paediatric Intensive Care Unit in the Northwest of England. Over 1000 children are admitted each year, with around $85 \%$ of these being intubated. We report the first month's results

Results: All children admitted in November 2009 were audited. Of 101 children admitted to PICU, 75 had at least one test of coagulation. 37 of these were admitted with a cardiac diagnosis, 38 had a general diagnosis. In total 4 children died. In all 402 tests were done and $287(71 \%)$ of these tests were abnormal. In response to coagulation abnormalities demonstrated on laboratory testing. FFP, cryoprecipitate or platelets, were given on a total of 80 occasions to 18 children. If children received blood-derived-clotting factors most often this was only on one occasion. This was highly variable. One child who stayed 27 days had 84 tests, all of which we abnormal, receiving factor correction on 40 occasions.

Conclusions: Many coagulation tests are performed in critical care. Often, even when the results are abnormal, no action is taken. It is likely that a more judicious approach to sampling will be reflected in lower costs and higher haemoglobin levels or reduced transfusion requirement. Further work is continuing.

\section{2}

\section{MODEL OF CARDIOLOGY SERVICE IN DISTRICT GENERAL HOSPITAL}

\author{
P.R. Prasannan, S. Jaiswal \\ Paediatrics, Frimley Park Hospital NHS \\ Foundation Trust, Camberley, UK
}

Background: Various models of cardiology service are available in district general hospitals (DGH) 